\title{
Study on Variation in Seed Morphology, Oil Content and Fatty Acid Profile of Madhuca longifolia Grown in Different Agro-Climatic Zones in Sri Lanka
}

\author{
Mihiri Munasinghe*, Jagath Wansapala \\ Department of Food Science and Technology, Faculty of Applied Sciences, University of Sri Jayewardenepura, Gangodawila, Nugegoda, Sri \\ Lanka
}

\author{
Email address: \\ mihirimunasinghe@gmail.com (M. Munasinghe)
}

\section{To cite this article:}

Mihiri Munasinghe, Jagath Wansapala. Study on Variation in Seed Morphology, Oil Content and Fatty Acid Profile of Madhuca longifolia Grown in Different Agro-Climatic Zones in Sri Lanka. Science Research. Vol. 3, No. 3, 2015, pp. 105-109. doi: 10.11648/j.sr.20150303.20

\begin{abstract}
The aim of this study was to determine the variation in morphology of seeds, seed oil content and the fatty acid profile of $M$. longifolia and, to find the relationship between oil content and fatty acid composition with environmental conditions. Seeds were collected representing four agro-climatic zones in Sri Lanka. The length $(2.7333-3.4333 \mathrm{~cm})$, width $(1.0633-1.2967 \mathrm{~cm})$ and the weight $(0.9262-1.4018 \mathrm{~g})$ were determined in seeds. Significant differences were there within agro-climatic zones. Oil from seed kernel was extracted with Soxhlet method using $n$-Hexane (bp. $65-70^{\circ} \mathrm{C}$ ) and the fatty acid profile was determined using GC-MS (Gas chromatography-Mass spectrophotometry). Results reveal significant differences in oil content (50.07-53.85\%) among agro-climatic zones. As the major fatty acids, Oleic, Stearic, Palmitic and Linoleic were resulted in all four agro-climatic zones. The total saturated fatty acid content (C18:0, C16:0, C14:0, C17:0, C19:0, C22:0, $\mathrm{C} 24: 0, \mathrm{C} 26: 0, \mathrm{C} 20: 0$ and $\mathrm{C} 8: 0)$ varied from 40.87-47.20\%. However the total unsaturated fatty acid content (C16:1, C18:1, C18:2, C20:1) was within the range of 49.6-53.86\% (TMUFA+TPUFA), here the highest content was recorded in low country intermediate zone and the lowest in mid country intermediate zone. Oil content and the fatty acid composition were not correlated with the studied geographical parameters.
\end{abstract}

Keywords: Fatty Acid Composition, Seed Oil, Oil Extraction, Morphology

\section{Introduction}

Madhuca longifolia (Family: Sapotaceae) is an important economic tree growing throughout the subtropical region of the Indo-Pak subcontinent including northern, central and southern part of peninsular India, Sri Lanka and Burma. There are two varieties of this plant as Madhuca longifolia (Koenig) J.F. Macb. var. longifolia and Madhuca longifolia (Koenig) J.F. Macb. var. latifolia (Roxb.) Cheval. Of the two varieties, var. longifolia is distributed in Sri Lanka, Southern India extending northwards to Maharashtra and Gujrat; var. latifolia is found in some parts of central and north India and Burma (Ramadan et al., 2006; Akshatha et al., 2013). This plant plays a significant role in both Indian and Sri Lankan traditional ayurvedic medicines. In ayurvedic, this is highly regarded as a universal panacea since it can be used to treat a wide range of illnesses. Almost all the parts of the plant including bark, flowers, seeds and leaves are used for that. The strong, hard and durable heartwood of the tree is used for house construction like activities. Flowers are edible and used as a food item of tribal either in raw or cooked forms. They are fermented to produce an alcoholic drink called as Mahua, country liquor (Kundu, 2012). This liquor is used to produce vinegar also. The plant produces fruit, valued for its seeds, which are the largest source of natural hard fat (ca. $50 \%$ ), commercially known as mahua butter or mowrah butter, and has many other edible, medicinal and industrial applications (Sastri, 1962; Bringi, 1987; Singh and Singh, 1991). The crude oil extracted from the seeds is pale yellow and remains as a semi-solid in the tropical temperatures (Marikkar and Yanty, 2012).Oleic acid (46.3\%), palmitic acid (17.8\%), stearic acid (14.0\%), and linoleic acid (17.9\%) have identified as the major fatty acids in M. longifolia seed oil (Singh and Singh, 1991). According to Ramadan et al., (2006), about $46 \%$ of the fatty acids present in M. longifolia seed oil is saturated, $37.4 \%$ mono unsaturated, and $16.5 \%$ poly unsaturated. Therefore it seems that it contains necessary amount of essential fatty acids. The predominance 
of mono unsaturation likens mahua fat to olive oil which has been found by nutritionists to be as effective as polyunsaturated oil in reducing blood cholesterol, hence reducing the incidence of coronary heart disease (CHD) (Lawson, 1995).These characteristics in M. longifolia seed fat make it a high quality food.

The oil yield from the crops is always the key factor to decide its suitability for nutritional and industrial purposes from economic point of view (Yadav et al., 2011). In that case, $M$. longifolia yields a considerable amount of oil as mentioned previously. But the use of this oil for the food industry has been carried out in a limited scale. In Sri Lanka, almost all these edible purposes have limited only for cooking in traditional culture. This also is in very small scale and considers that seeds as an under-utilized seed type for the production of oil. According to the past reports, the under-utility of this fat may probably due to the lack of technical information regarding this tree. Few reports can be found with the literature highlighting the fatty acid profile, thermal characteristics, and the bio active constituents of $M$. longifolia oil.

However these previous researches have focused on the chemical composition of $M$. longifolia seed oil, there is no data about the variation of morphology in seed material, its fatty acid profile and the effect of geographical and environmental factors on them. In economic point of view, it is important to identify this natural variation to improve the quality of plant for different purposes. Studying this variation may help to identify the plants with best fatty acid profile which suits for different economic applications (different industries). Therefore, the aim of this study was to identify the variation in morphology of seeds and to quantify the variation in fatty acid profile and oil content in several agroclimatic zones in Sri Lanka and to determine the relationship between those characteristics with some geographical factors.

\section{Materials and Methods}

\subsection{Seed Material Collection}

The dried, fallen fruit seeds of M. longifolia were collected from four different agro-climatic zones in Sri Lanka during August-December 2014 using the random sampling method. Even though there are seven agro-climatic zones in Sri Lanka, these four were selected for the study based on the availability of plant. The four agro-climatic zones were low country dry zone (LD), low country wet zone (LW), low country intermediate zone (LI) and mid country intermediate zone (MI). The geographical characteristics and the soil type of the selected area were recorded. Table 1 shows the geographical data where the samples were collected. The collected samples were named with symbols as LD, LW, LI and MI with respect to their agro-climatic zone. The species and the variety of the plant were confirmed by comparing the morphological characteristics.

Table 1. Eco-systems where M. longifolia seed samples were collected.

\begin{tabular}{|c|c|c|c|c|c|c|}
\hline \multirow{2}{*}{$\begin{array}{l}\text { Sample } \\
\text { symbols }\end{array}$} & \multirow{2}{*}{ Agro-climatic zone } & \multirow{2}{*}{$\begin{array}{l}\text { Annual rain } \\
\text { fall(mm) }\end{array}$} & \multirow{2}{*}{ Soil type } & \multicolumn{3}{|c|}{ Geographic parameters } \\
\hline & & & & Latitude & Longitude & Altitude (m) \\
\hline LD & Low country dry zone & $1000-1500$ & Reddish Brown Earth & 8.32 & 80.40 & 92 \\
\hline LW & Low country Wet zone & $2500-3000$ & Red Yellow Podsolic & 6.17 & 80.18 & 86 \\
\hline LI & Low country Intermediate zone & $1500-2000$ & Red Yellow Podsolic & 7.65 & 80.50 & 149 \\
\hline MI & Mid country Intermediate zone & $1500-2000$ & Sub group with a strongly mottled subsoil & 7.66 & 80.63 & 352 \\
\hline
\end{tabular}

\subsection{Determination of Morphological Differences in Seeds}

The basic morphological characteristics of the seeds including the length, width and the weight were determined $(n=30)$.

\subsection{Oil Extraction}

The total oil content of seed kernels was determined using the Soxhlet system according to the AOAC method (AOAC, 1990). Preliminary tests were performed to select the optimal conditions that give the highest yield of oil (solvent and extraction time). For that, oil extraction was carried out for $6 \mathrm{hrs}, 5 \mathrm{hrs}$ and $4 \mathrm{hrs}$ with $n$-Hexane (bp.65-70 C) and Petroleum ether $\left(\mathrm{bp} .40-60^{\circ} \mathrm{C}\right)$. When consider about the extraction time, the majority $(99 \%)$ of yield was obtained during the first $4 \mathrm{hrs}$. Best organoleptic properties (especially with respect to odor) as well as the best appearance and clear oil were obtained with n-Hexane compared to pet ether. Therefore, 4 hrs extraction time with $n$-Hexane was used as the method of oil extraction for all samples. The sample of 5 $\mathrm{g}$ was placed in the Soxhlet extraction apparatus and it was extracted for $4 \mathrm{hrs}$. The extracted oil was weighed and the yield was calculated as the percentage. The oil was stored in a refrigerator $\left(4^{\circ} \mathrm{C}\right)$ for the determination of fatty acid profile.

\subsection{Determination of Variation in Fatty Acid Profile}

Fatty acid methyl esters (FAMEs) were prepared using the method described by ITI, Sri Lanka (Anonymous, n.d., Method manual for preparation of fatty acid methyl esters, ITI, Sri Lanka). They were identified on Gas Chromatograph (GC) model-7890 A, Agilent technologies equipped with Mass Spectrometer (MS) model-5975 C inert XL EI/CI MSD with triple-axis detector. Nitrogen was used as the carrier gas with a flow rate of $1 \mathrm{ml} / \mathrm{min}$. A polar capillary column RTX-5, $0.32 \mathrm{~mm}$ internal diameter, $30 \mathrm{~m}$ length and $0.25 \mu \mathrm{m}$ film thickness (Restex Corp., Bellefonte, PA, USA) was used for the separation of FAMEs. The injection volume of the sample was $2 \mu \mathrm{l}$ and it was injected at a temperature of $270{ }^{\circ} \mathrm{C}$. The initial column temperature was $100{ }^{\circ} \mathrm{C}$ programmed by 20 ${ }^{\circ} \mathrm{C} / \mathrm{min}$ until $170{ }^{\circ} \mathrm{C}$ (hold time $0 \mathrm{~min}$ ), then $2{ }^{\circ} \mathrm{C} / \mathrm{min}$ until $230{ }^{\circ} \mathrm{C}$ (hold time $0 \mathrm{~min}$ ) and finally $5{ }^{\circ} \mathrm{C} / \mathrm{min}$ until $280{ }^{\circ} \mathrm{C}$ (hold time $16.5 \mathrm{~min}$ ). The total run time of the sample was 60 min. The percentage of fatty acids was calculated as the ratio 
of the partial area to the total peak area of FAMEs.

\subsection{Statistical Analysis}

Data collected were analyzed using the Minitab 17 statistical software. One way analysis of variance was performed to compare the length, width and the weight of seeds in different agro-climatic zones. Mean comparisons were done with the Tukey test at 5\% significant level. Mean oil content in four agro-climatic zones was assessed for significant differences using Fisher LSD method at 5\% significant level. Spearman Rho correlation was also calculated for oil content and fatty acid composition with geographical factors.

\section{Results and Discussion}

\subsection{Determination of Morphological Differences in Seeds}

Table 2. Morphological differences in seeds collected from different agroclimatic zones.

\begin{tabular}{lllll}
\hline Seed character & LD & LW & LI & MI \\
\hline Length $(\mathrm{cm})$ & $2.7467^{\mathrm{b}}$ & $2.7333^{\mathrm{b}}$ & $3.3667^{\mathrm{a}}$ & $3.4333^{\mathrm{a}}$ \\
Width $(\mathrm{cm})$ & $1.0633^{\mathrm{b}}$ & $1.1200^{\mathrm{b}}$ & $1.2967^{\mathrm{a}}$ & $1.1133^{\mathrm{b}}$ \\
Weight $(\mathrm{g})$ & $1.0781^{\mathrm{b}}$ & $0.9262^{\mathrm{c}}$ & $1.4018^{\mathrm{a}}$ & $1.0575^{\mathrm{b}}$ \\
\hline
\end{tabular}

Means that do not share a letter are significantly different at significant level 0.05 (Tukey test).

When consider about the length of seeds, the highest mean length was recorded for the sample obtained from mid country intermediate zone $(3.4333 \mathrm{~cm})$. The lowest value has obtained from Low country wet zone $(2.7333 \mathrm{~cm})$. As shown in Table 2, the results are significantly different $(\mathrm{P}<0.05)$ ranging the length $2.7333 \mathrm{~cm}$ for low country wet zone and $3.4333 \mathrm{~cm}$ for mid country intermediate zone. In case of width, the sample obtained from low country intermediate zone has shown the highest value for the width $(1.2967 \mathrm{~cm})$ relatively to other 3 and it is significantly different from those 3 also. The weight of seeds ranged from $0.9262 \mathrm{~g}$ to $1.4018 \mathrm{~g}$ and the resulted weights are significantly different. There was no significant difference between the 2 samples obtained from low country dry zone and mid country intermediate zone.

Forest tree populations, compared to agricultural crops, have been influenced little by human activities until now. In fact, trees like jatropha, mahua (M. longifolia), neem and many other important tree species have not been subjected to any genetic improvement efforts and, therefore, are considered to possess greater natural variability compared to other crop plants. Moreover, it is an established fact that tree species with a wide geographical distribution exhibit considerable anatomical, physiological, morphological and genetical variability to survive under varying environmental conditions (Kaura et al., 1998; Kaushik et al., 2007). When consider about the seed samples used for this study, they were obtained from the plants grown in different areas with different climatic and environmental conditions (as shown in Table 1). That might be the reason for these morphological differences in seeds.

\subsection{Variation in Oil Content and Fatty Acid Profile}

The mean oil content in seed kernels obtained from different agro-climatic zones was ranged from 50.07-53.85\%, exhibiting the highest oil yield in low country dry zone and the least in mid country intermediate zone. There were significant differences $(\mathrm{P}<0.05)$ among four agro-climatic zones for oil content. In the fatty acid profile, 15 fatty acid types were identified as a whole. They were Oleic (C18:1), Linoleic (C18:2), Stearic (C18:0), Palmitic (C16:0), Myristic (C14:0), Palmitoleic (C16:1), Margaric (C17:0), Nonadecylic (C19:0), cis-Gondoic (C20:1), Behenic (C22:0), Lignoceric (C24:0), Cerotic (C26:0), Arachidic (C20:0), Palmitelaidic (C16:1) and Caprylic (C8:0). Among these, Oleic, Stearic, Palmitic and Linoleic were the major fatty acids as shown in Fig. 1 and these results are in agreement with the previous studies (Singh and Singh, 1991). Others can be found in trace amounts. The Stearic acid content ranged from 13.70-24.50\% and the highest value $(24.50 \%)$ was recorded in low country intermediate zone. The least value $(13.70 \%)$ was there in mid country intermediate zone. In here, mid country intermediate zone has shown relatively a less amount of Stearic acid compared to other 3 agro-climatic zones. For Palmitic acid, mid country intermediate zone has the highest value $(26.52 \%)$ and low country intermediate zone has the lowest value $(19.12 \%)$. The Oleic acid content was within the range of $40.44-50.32 \%$ showing the highest amount (50.32\%) in low country dry zone and the least in mid country intermediate zone $(40.44 \%)$. The highest amount of Linoleic acid $(9.16 \%)$ has recorded in mid country intermediate zone and the lowest in low country dry zone $(2.49 \%)$.

Table 3. Mean Oil content and fatty acid profile based on agro-climatic zone.

\begin{tabular}{|c|c|c|c|c|c|c|c|c|c|}
\hline \multirow{2}{*}{$\begin{array}{l}\text { Sample } \\
\text { symbol }\end{array}$} & \multirow{2}{*}{$\begin{array}{l}\text { Oil content } \\
(\%)\end{array}$} & \multicolumn{2}{|c|}{$\begin{array}{l}\text { Saturated fatty acid } \\
\text { content }(\%)\end{array}$} & \multicolumn{2}{|c|}{ Unsaturated fatty acid content $(\%)$} & \multirow{2}{*}{ TSFA } & \multirow{2}{*}{ TMUFA } & \multirow{2}{*}{ TPUFA } & \multirow{2}{*}{ PUFA/SFA } \\
\hline & & $\begin{array}{l}\text { Stearic } \\
\text { (C18:0) }\end{array}$ & $\begin{array}{l}\text { Palmitic } \\
\text { (C16:0) }\end{array}$ & Oleic (C18:1) & Linoleic (C18:2) & & & & \\
\hline LD & $52.22^{\mathrm{b}}$ & 24.18 & 23.02 & 50.32 & 2.49 & 47.20 & 50.32 & 2.49 & 0.05 \\
\hline LW & $51.69^{b}$ & 24.36 & 22.16 & 44.06 & 8.84 & 47.07 & 44.06 & 8.84 & 0.19 \\
\hline LI & $53.85^{\mathrm{a}}$ & 24.50 & 19.12 & 48.31 & 5.51 & 46.14 & 48.75 & 5.11 & 0.11 \\
\hline MI & $50.07^{\mathrm{c}}$ & 13.70 & 26.52 & 40.44 & 9.16 & 40.87 & 40.44 & 9.16 & 0.22 \\
\hline
\end{tabular}

Oil content determined as the mean of 6 replicates, Means that do not share a letter are significantly different at significant level 0.05 (Fisher LSD test), Fatty acids as the mean of 2 replicates.

TSFA-Total saturated fatty acids, TMUFA-Total Mono unsaturated fatty acids, TPUFA-Total poly unsaturated fatty acids and PUFA/SFA- The ratio of Poly unsaturated fatty acids/Saturated fatty acids 
As shown in Table 3, the lowest total saturated fatty acid content $(40.87 \%)$ is there in mid country intermediate zone as well as the highest $(47.20 \%)$ can be seen in low country dry zone. The sample obtained from low country dry zone was rich with mono unsaturated fatty acids $(50.32 \%)$ compared to other 3 agro-climatic zones. Here, the lowest TMUFA content was $40.44 \%$ and it has recorded in mid country intermediate zone's sample. The total polyunsaturated fatty acid content was high in mid country intermediate sample $(9.16 \%)$ and it was low in the sample of low country dry zone $(2.49 \%)$. The highest $(0.22)$ and the lowest $(0.05)$ ratios of poly unsaturated fatty acids to saturated fatty acids were also same as this.

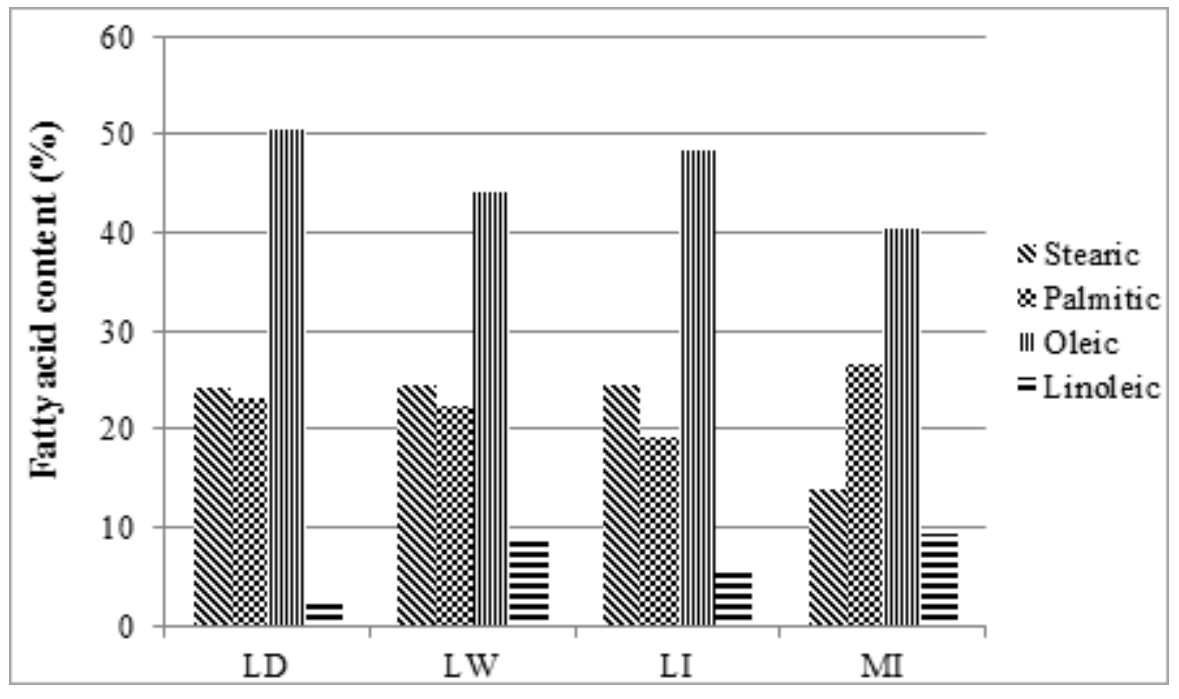

Fig. 1. Fatty acid profile of M. longifolia growing in different agro-climatic zones.

Results indicate that there is a considerable variation among the individual fatty acid contents obtained from different agro-climatic zones. It is well-known that the fatty acid composition is much influenced by environment factors (climate, soil type, etc.) and genetic factors under which they are grown (Aabd et al., 2013).

Table 4. Spearman Rho correlation between geographical factors, oil content and fatty acid profile.

\begin{tabular}{|c|c|c|c|c|c|c|}
\hline & Oil content $(\%)$ & C18:0 & C16:0 & C18:1 & C18:2 & PUFA/SFA \\
\hline Altitude (m) & -0.200 & -0.400 & 0.400 & -0.400 & 0.400 & 0.400 \\
\hline Latitude & 0.000 & -0.600 & 0.600 & 0.400 & -0.400 & -0.400 \\
\hline Longitude & -0.200 & -0.400 & 0.400 & -0.400 & 0.400 & 0.400 \\
\hline
\end{tabular}

No significant Correlations at significant level 0.05

The correlation between geographical factors, oil content and the fatty acid profile was studied as shown in Table 4 . No significant correlation found between oil content and all the fatty acid types with geographical factors. With these results, it is difficult to establish a relationship between the oil content and fatty acid profile with geographical factors here studied. This suggests that the variation we observed in the fatty acid composition is associated with other factors. The fatty acid biosynthesis pathway is carried out in the plant leaf. Accordingly, this endogenous synthesis and elongation are linked to physiological plant processes (structure, enzymatic activities etc.) and genotype- environment interaction is considered during seed development (Aabd et al., 2013).

\section{Conclusion}

Although $M$. longifolia is a locally available plant in Sri Lanka, studies regarding its seed oil are limited. Especially, the impact of geographical factors on the variation of seed properties (morphology, oil content and fatty acid profile) cannot be found at all. In concluding this study, morphological characteristics of seeds (length, width and the weight) differ significantly in four agro-climatic zones. Oil content (50.07-53.85\%) was also significantly different for four agro-climatic zones. Oleic, Linoleic, Palmitic and Steric were the predominant fatty acids in all 4 agro-climatic zones. The percentages of four prominent fatty acid types were varied considerably among 4 agro-climatic zones showing the effect of locality on the fatty acid composition. Oil content and the Fatty acid composition were not correlated with the studied geographical factors but, there can be the impact of other environmental conditions.

\section{References}

[1] Aabd N. A., Asbahani A. E., Alem Y. E., Finti A. E., Msanda F. and Mousadik A.E. (2013) Variation in oil content and fatty acid composition in preselected argan trees with morphological characters and geographical localization. Mediterranean Journal of Nutrition and Metabolism. 6(3): 217-225 
[2] Akshatha K. N., Mahadeva Murthy S., and Lakshmidevi N. (2013) Ethno medical uses of Madhuca longifolia - a review. International Journal of Life Science \& Pharma Research. $3(1): 44-53$

[3] AOAC (1990) Official methods of analysis, 15th edn. Association of Official Analytical Chemists, Inc., Virginia: 770-771

[4] Bringi N. V. (1987). Non-traditional oilseed and oils in India. Oxford and I.B.H. Publishing: 109-117

[5] Kaura S. K., Gupta S. K. and Chowdhury J. B. (1998) Morphological and oil content variation in seeds of Azadirachta indica A. Juss. (Neem) from northern and western provenances of India. Plant Foods for Hum Nutr.52: 293-298

[6] Kaushik N., Kumar K., Kumar S. and Kaushik N., Roy S. (2007) Genetic variability and divergence studies in seed traits and oil content of Jatropha (Jatropha curcas L.) accessions. Biomass and Bioenergy. 31: 497-502

[7] Kundu M. (2012) Madhuca longifolia (Koenig) J. F. Macb. Seed leaflet
[8] Lawson H. (1995) Nutritional aspects of oils and fats. In: Lawson $\mathrm{H}$ (ed) Food oils and fats, technology, utilization and nutrition. Chapman and Hall, USA: 203-280

[9] Marikkar J. M. N. and Yanty N. A. M. (2012). Seed fat from Madhuca longifolia as raw material for Halal alternative fats. BORNEO SCIENCE. 31: 84-93.

[10] Ramadan M. F., Sharanabasappa G., Parmjyothi S., Seshagiri M. and Moersel Joerg-Thomas (2006) Profile and levels of fatty acids and bioactive constituents in mahua butter from fruit-seeds of buttercup tree [Madhuca longifolia (Koenig)]. Eur Food Res Technol. 222: 710-718

[11] Sastri M. W. (1962).the wealth of India raw material. New Delhi, India: CSIR: 207.

[12] Singh A. and Singh I. S. (1991). Chemical evaluation of mahua (Madhuca indica) seed. Food Chem.40:8-221.

[13] Yadav S., Suneja P., Hussain Z., Abraham Z. and Mishra S. K. (2011) Genetic variability and divergence studies in seed and oil parameters of mahua (Madhuca longifolia Koenig) J.F. Macribide accessions. Biomass and bioenergy. 35: 1773-1778. 